\title{
Resposta do milho (Zea mays L.) à adubação foliar e via solo de nitrogênio
}

\author{
Roberto Kennedy Mortate ${ }^{1}$, Eduarda Fernanda Nascimento ${ }^{1}$, Edmar Gustavo de Souza \\ Gonçalves $^{2}$, Max Wendell de Paula Lima ${ }^{2}$
}

\author{
${ }^{1}$ Universidade Estadual de Mato Grosso do Sul, Unidade Universitária de Cassilândia, Cassilândia, Mato Grosso do Sul, Brasil. E- \\ mail: roberto.mortate@gmail.com, eduardafernanda71@gmail \\ ${ }^{2}$ Universidade do Estado de Minas Gerais, Unidade Ituiutaba, Ituiutaba, Minas Gerais, Brasil. E-mail: edmar_gustavo@ hotmail.com, \\ comlimamw@yahoo.com.br
}

Recebido: 31/10/2017; Aceito: 01/11/2017.

\section{RESUMO}

O presente trabalho teve por objetivo avaliar a resposta de plantas de milho submetidas a diferentes fontes de adubos nitrogenados. O experimento foi conduzido em um delineamento em blocos casualizados (DBC), com quatro tratamentos e cinco repetições, totalizando 20 parcelas. Os tratamentos usados foram: $\mathrm{T} 1=\mathrm{controle}(\mathrm{sem}$ aplicação de N), T2= $300 \mathrm{~kg} \mathrm{ha}^{-1}$ de sulfato de amônio $\left(18 \%\right.$ de N), T3= $200 \mathrm{~kg} \mathrm{ha}^{-1}$ de ureia $(45 \%$ de N) e T4=2 $\mathrm{L} \mathrm{ha}^{-1}$ de Fortune ${ }^{\circledR}(20 \%$ de $\mathrm{N})$, os quais foram aplicados em adubação de cobertura via solo e via foliar, conforme especificidade de cada produto, entre os estádios fenológicos $\mathrm{V}_{6} \mathrm{e} \mathrm{V}_{8}$. Os parâmetros avaliados foram: clorofila total (SPAD), diâmetro de espigas $(\mathrm{cm})$, número de fileiras de grãos por espiga, massa de grãos por espiga (g), comprimento de espigas $(\mathrm{cm})$ e produtividade de grãos $\left(\mathrm{kg} \mathrm{ha}^{-1}\right)$. O tratamento T3 foi superior a todos os parâmetros avaliados, exceto quanto ao número de grãos por espiga que não apresentou diferenças estatísticas para nenhum tratamento. Concluiu-se que de fato, a demanda por $\mathrm{N}$ pelas plantas de milho é muito alta e que a mesma responde bem a adubação de cobertura com ureia e sulfato de amônio e que o fertilizante foliar Fortune ${ }^{\circledR}$ aplicado via foliar, pode contribuir para incremento na produtividade da cultura do milho, mas não consegue suprir a demanda de $\mathrm{N}$ pela cultura, quando aplicado como única forma de fornecimento de $\mathrm{N}$ inorgânico às plantas.

Palavras-chave: adubação nitrogenada, Fortune ${ }^{\circledR}$, produtividade de milho.

\section{Response of maize (Zea mays L.) to nitrogen fertilizer application in the soil and foliar}

\begin{abstract}
The objective of this work was to evaluate the response of maize plants submitted to application of nitrogen fertilizer sources. The experiment was conducted in a randomized block design (RBD), with four treatments and five replications, totaling 20 plots. The treatments used were $\mathrm{T} 1=$ control, $\mathrm{T} 2=300 \mathrm{~kg} \mathrm{ha}^{-1}$ of ammonium sulfate $(18 \%$ of $\mathrm{N}), \mathrm{T} 3=200 \mathrm{~kg} \mathrm{ha}^{-1}$ of urea $(45 \%$ of $\mathrm{N})$; and, T4= $2 \mathrm{~L} \mathrm{ha}^{-1}$ of Fortune ${ }^{\circledR}(20 \%$ of N), which were applied in the soil and via foliar, according to the specificity of each product, between phenological stages $\mathrm{V}_{6}$ and $\mathrm{V}_{8}$. The parameters evaluated were total chlorophyll (SPAD), spike diameter $(\mathrm{cm})$, number of grain rows per spike, grain mass per spike $(\mathrm{g})$, length of spike $(\mathrm{cm})$ and grain yield $\left(\mathrm{kg} \mathrm{ha}^{-1}\right)$. The T3 treatment was superior to all evaluated parameters, except for the number of grains per spike that did not present statistical differences for any treatment. It was concluded that the demand for $\mathrm{N}$ by maize plants is very high and that it responds well to urea and ammonium sulfate fertilization and that Fortune ${ }^{\circledR}$ fertilizer applied via foliar can contribute to an increase in maize yield, but fails to supply the $\mathrm{N}$ demand by the crop, when applied as the only way of supplying inorganic $\mathrm{N}$ to the plants.
\end{abstract}

Key words: nitrogen fertilization, Fortune ${ }^{\circledR}$, corn yield. 


\section{Introdução}

No Brasil, a cultura do milho tem grande importância no agronegócio, e contribui para o sustento de pequenas propriedades. O milho representa cerca de $30 \%$ da área total cultivada do país, somente a soja ultrapassa esse número de área cultivada (CONAB, 2013). O milho responde muito bem aos fertilizantes, sendo uma das culturas mais exigentes em adubos nitrogenados. Diante de níveis adequados, ocorrem incrementos significativos em várias características que influenciam a produção final (OHLAND et al., 2005). Todavia, o nitrogênio (N) apesar de ser considerado o nutriente indispensável para se alcançar alta produtividade, devido ao teor proteico dos grãos, o $\mathrm{N}$ é também o elemento que mais contribui para o aumento dos custos na cultura do milho.

Atualmente se faz a adubação nitrogenada na cultura do milho em duas etapas; a primeira na semeadura onde se fornece uma parte da dose de $\mathrm{N}$ e a segunda etapa quando a planta apresentar o estádio $V_{4}$ até $V_{8}$, aplicando-se o restante. Mesmo assim, na cultura do milho, o aproveitamento do adubo nitrogenado fica em torno dos $50 \%$ do aplicado como fertilizante mineral (LARA CABEZAS et al., 2004).

Os fertilizantes nitrogenados mais utilizados são a uréia e o sulfato de amônio e estão sujeitos a perdas por lixiviação, escoamento superficial, volatilização da amônia ou imobilização na biomassa microbiana (ALVA et al., 2005). A ureia é a mais utilizada por apresentar maior concentração de $\mathrm{N}$ e por apresentar menor custo-benefício, quando comparados a outras fontes de adubos nitrogenados. $\mathrm{O}$ aumento da produtividade de grãos depende de vários fatores, principalmente da eficiência da absorção de $\mathrm{N}$ pela planta e sua translocação para os grãos.

Diante da necessidade de melhor absorção de $\mathrm{N}$ pelas plantas, a suplementação nitrogenada através de pulverização via foliar deve ser empregada. Esta prática pode ser conveniente e rápida, melhorando as respostas ao mineral, contribuindo para o crescimento da planta e corrigindo deficiências nutricionais em estádios já avançados, diante do tempo de absorção e resposta. A aplicação foliar tem sido um meio eficiente de se fornecer $\mathrm{N}$ às plantas e a uréia auxilia na absorção dos micronutrientes presentes na solução aplicada nas folhas, propiciando maior produtividade das plantas (BOARETTO et al., 1999).

Diante das informações mencionadas, o presente trabalho teve por objetivo avaliar a produtividade de milho, sob diferentes adubações de cobertura, aplicadas via solo e via foliar.

\section{Material e Métodos}

O experimento foi conduzido a campo no município de Ituiutaba-MG entre os meses de junho a outubro do ano de 2016, nas dependências da Universidade do Estado de Minas Gerais-(UEMG) Unidade Ituiutaba. A localidade tem temperatura média de $23.9^{\circ} \mathrm{C}$ e média anual de pluviosidade de $1.352 \mathrm{~mm}$ e está sob as coordenadas: latitude: $18^{\circ} 58^{\prime} 08^{\prime \prime} \mathrm{S}$, longitude: $49^{\circ} 27^{\prime}$ $54 " \mathrm{~W}$ e altitude de $544 \mathrm{~m}$. As características químicas do solo na camada $0-20 \mathrm{~cm}$ de profundidade, na área do experimento podem ser observadas na Tabela 1 .

Tabela 1: Caracterização química de solo, na camada até $20 \mathrm{~cm}$ de profundidade (UEMG-Ituitaba, 2016).

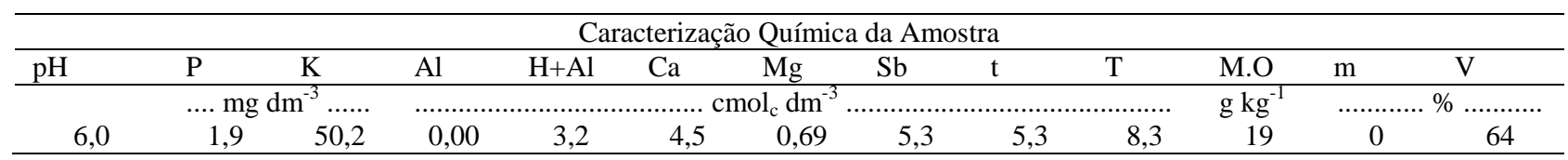

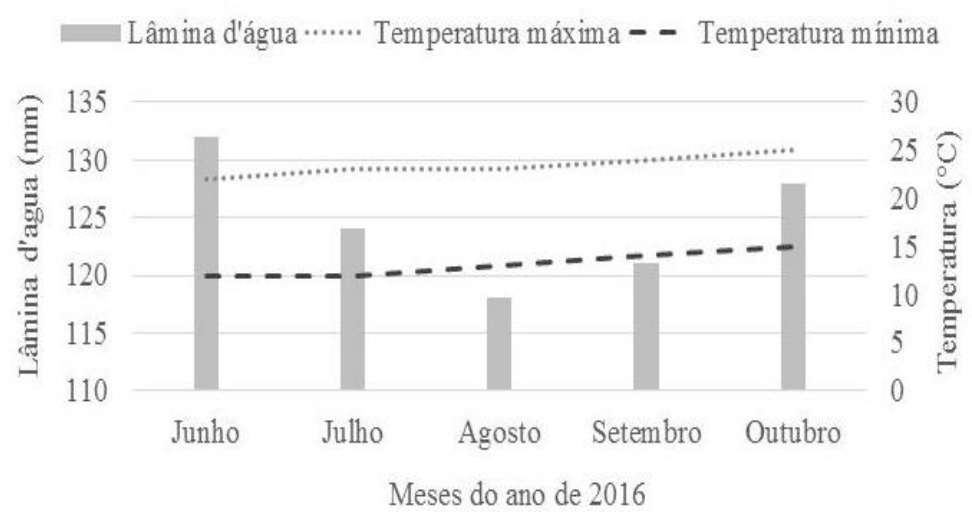

Figura 1: Temperaturas $\left({ }^{\circ} \mathrm{C}\right)$ mínima, máxima e precipitação $(\mathrm{mm})$ durante o período de avaliações do experimento. Os dados foram coletados com auxílio de pluviômetros e termômetro de máxima e mínima o longo do experimento. 
A cultura utilizada foi o milho (Zea mays L.), com o híbrido BIOMATRIX VT PRO $2^{\circledR}$ semeado a campo com uma população de 60.000 plantas ha ${ }^{-1} \mathrm{e}$ as sementes já tratadas previamente com fungicida e inseticida. Todos os tratamentos foram adubados na linha de plantio com adubo NPK (04-14-08), na proporção de $400 \mathrm{~kg} \mathrm{ha}^{-1}$ no momento do plantio, realizado manualmente com uma densidade de plantio de 5 sementes $\mathrm{m}^{-1}$. O delineamento utilizado foi em blocos casualizados (DBC), com quatro tratamentos (descritos na Tabela 2 e cinco repetições, totalizando vinte parcelas; cada parcela composta de três linhas com espaçamento de $0,8 \mathrm{~m}$ e $3,0 \mathrm{~m}$ de comprimento, totalizando $7,2 \mathrm{~m}^{2}$; e área total do experimento de 144 $\mathrm{m}^{2}$.

A adubação de cobertura dos tratamentos T2 e T3 foi feita via solo; para se encontrar a quantidade necessária para cada parcela realizou-se o cálculo proporcional à dosagem utilizada por hectare $\mathrm{e}$ distribuído uniformemente sobre a superfície de toda a área da parcela de forma manual.

O Tratamento T4, fertilizante líquido comercial denominado Fortune ${ }^{\circledR}$, possui a formulação: $20 \%$ de Nitrogênio, 5\% de Fósforo, 5 Potássio, 0,05\% de Cobre, 0,1\% de Molibdênio, 0,5\% de Zinco, 0,2\% de Boro e $0,1 \%$ de Manganês por litro. Para aplicar o fertilizante via foliar utilizou-se um pulverizador costal com vazão de $200 \mathrm{~L} \mathrm{ha}^{-1}$; a quantidade do produto foi calculada proporcionalmente a $2 \mathrm{~L} \mathrm{ha}^{-1}$.

Tabela 2: Tratamentos utilizados em experimento a campo em DBC com cinco repetições (UEMG-Ituiutaba, 2016).

\begin{tabular}{cc}
\hline Tratamentos & Adubação em cobertura \\
\hline T1 & Controle \\
T2 & Sulfato de Amônio $\left(300 \mathrm{~kg} \mathrm{ha}^{-1}\right)$ \\
T3 & Ureia $\left(300 \mathrm{~kg} \mathrm{ha}^{-1}\right)$ \\
T4 & Fortune $\left(2 \mathrm{~L} \mathrm{ha}^{-1}\right)$ \\
\hline
\end{tabular}

A calda foi preparada individualmente para cada uma das cinco repetições do T4 e pulverizada totalmente sobre a área da parcela. As adubações de cobertura (via solo e via foliar) foram realizadas no mesmo momento, entre os estádios V6 e V8 das plantas.

Por ocasião de falta de chuva na época do ensaio, fez-se irrigação com auxílio de micro-aspersores sempre que necessário e a lâmina d'água foi medida com auxílio de pluviômetros distribuídos na área das parcelas (Figura 1).

Na ocasião da coleta dos dados, utilizou-se somente a linha central de cada parcela, descartando $0,5 \mathrm{~m} \mathrm{da}$ mesma em cada extremidade, restando $2 \mathrm{~m}$ úteis da fileira central em cada parcela para avaliação. A colheita foi realizada, manualmente, quando o milho apresentava maturação fisiológica. Para coleta dos dados foram utilizadas seis espigas sem palhas de cada parcela. Durante o período do florescimento, avaliou-se o teor relativo de clorofila nas folhas. Foram escolhidas duas plantas, na linha central das parcelas, para realizar a leitura com o medidor de clorofila portátil CLOROFILOG FALKER ${ }^{\circledR}$. Em cada planta realizaramse duas leituras, sendo uma na parte abaxial e uma na parte adaxial); diâmetro de espigas (mediu-se com paquímetro no centro das espigas e os resultados são dados $\mathrm{em} \mathrm{cm}$ ); número de fileiras de grãos por espiga (partiu-se as espigas ao meio e fez-se a contagem das fileiras de grãos e os resultados expressos em unidade); massa de grãos por espiga (as espigas foram debulhadas manualmente e com a pesagem dos grãos calculou-se a massa média de cada espiga e os resultados expressos em $\mathrm{g}$ ); comprimento de espigas (as espigas foram medidas com auxílio de uma régua graduada e os resultados expressos em $\mathrm{cm}$ ); produtividade (calculouse a produtividade utilizando a população de plantas multiplicada pela massa de grãos por espiga e os resultados expressos em $\mathrm{kg} \mathrm{ha}^{-1}$ ).

O teor de umidade dos grãos foi corrigido para 13\% a partir de determinação de umidade direta realizada em estufa de secagem à temperatura de $105^{\circ} \mathrm{C}$ por $24 \mathrm{~h}$. Os resultados obtidos foram submetidos à análise de variância e as médias comparadas pelo teste de Tukey ao nível de 5\% de probabilidade.

\section{Resultados e Discussão}

De acordo com a Tabela 3 observou-se que os Tratamentos T3 e T2 apresentaram melhores índices de SPAD, diferenciando-se dos T1 e T4.

De acordo com Chapman e Barreto (1997), tal resultado se deve às altas concentrações de $\mathrm{N}$ nos tratamentos T2 e T3; a relação entre o teor de nitrogênio e a leitura do índice SPAD se deve ao fato de que mais de $50 \%$ do nitrogênio total das folhas integram os compostos do cloroplasto e clorofila das folhas.

Resultado similar a este foi encontrado por Silveira et al. (2003) ao relatarem o aumento da leitura do índice SPAD em função de diferentes doses de nitrogênio na cultura do feijão.

Analisando a cultura do milho, esta mesma relação foi obtida por Jakelaitis et al. (2005) ao aumentarem o teor de nitrogênio de $25 \mathrm{~kg} \mathrm{ha}^{-1}$ para $75 \mathrm{~kg} \mathrm{ha}^{-1}$, refletindo diretamente na leitura SPAD, de 52,13 para 53,62 no período de florescimento.

Ao se observar os valores dispostos na Tabela 3 referentes ao número de fileiras por espiga, não há diferenças significativas. Segundo Valderrama et al. (2011), esse resultado era esperado, considerando-se que o número de fileiras por espiga é uma característica genética do genótipo. Entretanto os tratamentos T2 e T3 apresentam melhor performance quando comparados aos demais e refletem diretamente no diâmetro de 
espiga. Tal fato ocorre devido à fase de formação de grãos em potencial em cada espiga e também da definição do tamanho de espiga que podem ser observados no estádio vegetativo $\mathrm{V}_{12}$ onde já é possível visualizar a arquitetura da planta. $\mathrm{O}$ diâmetro de espiga é definido conforme a fase de formação de grãos, ou seja, quando ocorre perda de duas a quatro folhas basais (MAGALHÃES; DURÃES, 2006). Tais resultados corroboram com os resultados obtidos neste ensaio, onde de acordo com a Tabela 3 os diâmetros das espigas do tratamento T3, apesar de não se diferenciarem do T2 apresentaram maiores diâmetros quando comparados aos T1 e T4.

Houve incrementos significativos na massa de grãos por espiga de todos os tratamentos avaliados (Tabela 4), com destaque para o T3 que apresentou maiores valores, seguidos do T2, T4 e T1. Apesar de não apresentar os melhores resultados, o T4 foi $60 \%$ mais eficiente que o T1 (controle). Tal fato deve ser considerado visto que foram aplicados somente $2 \mathrm{~L} \mathrm{ha}^{-1}$ do fertilizante foliar Fortune $^{\circledR}$. Souza et al. (2011) obtiveram resultados semelhantes em experimento com dosagens de $\mathrm{N}$, onde observaram aumento do número de grãos por fileira com a aplicação de até $142 \mathrm{~kg} \mathrm{ha}^{-1}$ de $\mathrm{N}$, o que reflete diretamente na massa de grãos por espiga. Godoy et al. (2011) também observaram aumento do número de grãos por fileira em doses crescentes de $\mathrm{N}$ em até 130 $\mathrm{kg} \mathrm{ha}^{-1}$, evidenciando a resposta positiva na adição de doses de $\mathrm{N}$ na massa de grãos por espiga.

É importante atentar para as adubações nitrogenadas, de modo que a quantidade de $\mathrm{N}$ aplicada na cultura do milho seja a mais exata possível; os excessos prejudicam a qualidade do meio ambiente e aumentam o custo de produção para o produtor, de outra maneira, quantidades deficientes comprometem a produtividade almejada (AMADO et al., 2002). Analisando esta relação de excessos e deficiências de $\mathrm{N}$ na cultura do milho, Silva et al. (2003) e Cardoso et al. (2010) são emblemáticos sobre os reflexos positivos da adubação nitrogenada sobre a massa das espigas de milho com e sem palha.

Um dos parâmetros determinantes de uma boa produtividade é o comprimento das espigas. Apesar dos dados referentes ao número de fileiras por espiga não apresentar diferenças significativas e o diâmetro das espigas pequenas diferenças, o comprimento das espigas influenciará diretamente no número de grãos por espiga e consequentemente na produtividade da cultura do milho. De acordo com a Tabela 4 o Tratamento T3 foi superior aos demais tratamentos, e o T2 superior aos $\mathrm{T} 1$ e T4, que por sua vez não apresentaram diferenças significativas estatisticamente entre si.

Tabela 3: Clorofila, diâmetro de espigas (mm) e número de fileiras de grãos por espiga (un). UEMG -Ituiutaba, 2016.

\begin{tabular}{|c|c|c|c|}
\hline Tratamentos & $\begin{array}{l}\text { Clorofila Total } \\
\text { (SPAD) }\end{array}$ & $\begin{array}{l}\text { Diâmetro de espigas } \\
\qquad(\mathrm{cm})\end{array}$ & $\begin{array}{c}\mathrm{n}^{\circ} \text { fileiras de grãos espiga }{ }^{-1} \\
\text { (un) }\end{array}$ \\
\hline $\mathrm{T} 1$ & $39,17 \mathrm{~b}$ & $4,0 \mathrm{~b}$ & $15,70 \mathrm{a}$ \\
\hline $\mathrm{T} 2$ & $52,62 \mathrm{a}$ & $4,27 \mathrm{ab}$ & $16,45 \mathrm{a}$ \\
\hline $\mathrm{T} 3$ & 56,62 a & $4,50 \mathrm{a}$ & $16,35 \mathrm{a}$ \\
\hline $\mathrm{T} 4$ & $44,12 \mathrm{~b}$ & $4,02 \mathrm{~b}$ & $15,75 \mathrm{a}$ \\
\hline DMS & 6,82 & 0,39 & 1,26 \\
\hline F & $26,4279 * *$ & $7,1250 * *$ & $0,75^{\mathrm{ns}}$ \\
\hline $\mathrm{CV} \%$ & 6,41 & 4,20 & 3,55 \\
\hline
\end{tabular}

** significativo ao nível de $1 \%$ de probabilidade $(\mathrm{p}<1 \%), 0,01 \leq \mathrm{p}<0,05$ - significativo ao nível de $5 \%$ de probabilidade, ns não significativo (p $\geq$ $5 \%$ ). Médias seguidas pela mesma letra na coluna não diferem estatisticamente entre si pelo teste de Tukey. T1= controle, T2=sulfato de Amônio $\left(300 \mathrm{~kg} \mathrm{ha}^{-1}\right), \mathrm{T} 3=$ Ureia $\left(300 \mathrm{~kg} \mathrm{ha}^{-1}\right), \mathrm{T} 4=$ Fortune $\left(2 \mathrm{~L} \mathrm{ha}^{-1}\right)$.

Tabela 4: Massa de grãos por espiga (g), comprimento de espigas $(\mathrm{cm})$ e produtividade $\left(\mathrm{kg} \mathrm{ha}^{-1}\right)$. UEMG -Ituiutaba, 2016

\begin{tabular}{cccc}
\hline Tratamentos & $\begin{array}{c}\text { Massa de grãos por espiga } \\
(\mathrm{g})\end{array}$ & $\begin{array}{c}\text { Comprimento de espigas } \\
(\mathrm{cm})\end{array}$ & $\begin{array}{c}\text { Produtividade } \\
\left(\mathrm{kg} \mathrm{ha}^{-1}\right)\end{array}$ \\
\hline T1 & $57,12 \mathrm{~d}$ & $12,47 \mathrm{c}$ & $3.453,3$ \\
T2 & $100,05 \mathrm{~b}$ & $15,22 \mathrm{~b}$ & $6.003,0$ \\
T3 & $122,40 \mathrm{a}$ & $17,67 \mathrm{a}$ & $7.344,0$ \\
T4 & $87,62 \mathrm{c}$ & $12,42 \mathrm{c}$ & $5.257,5$ \\
\hline DMS & 7,66 & 1,34 & - \\
F & $246,586 * *$ & $68,995 *^{2}$ & - \\
CV\% & 3,78 & 4,19 & - \\
\hline
\end{tabular}

** significativo ao nível de $1 \%$ de probabilidade $(\mathrm{p}<1 \%$ ), * $0,01 \leq \mathrm{p}<0,05$ - significativo ao nível de $5 \%$ de probabilidade, ns não significativo (p $\geq$ $5 \%$ ). Médias seguidas pela mesma letra na coluna não diferem estatisticamente entre si pelo teste de Tukey. T1= controle, T2=sulfato de Amônio $\left(300 \mathrm{~kg} \mathrm{ha}^{-1}\right), \mathrm{T} 3=$ Ureia $\left(300 \mathrm{~kg} \mathrm{ha}^{-1}\right), \mathrm{T} 4=$ Fortune $\left(2 \mathrm{~L} \mathrm{ha}^{-1}\right)$. 
Existem várias características que podem refletir na produtividade do milho, dentre as mencionadas, a massa de grãos por espiga recebe uma maior atenção, visto que este dado pode estimar a produtividade de uma área, apoiando-se no estande final de plantas por hectare.

Ao se observar a Tabela 4 todos os tratamentos apresentaram diferenças significativas, apresentando maior produtividade o $\mathrm{T} 3$, seguido do $\mathrm{T} 2$, T4 e $\mathrm{T} 1$ sucessivamente. Isto se deu devido à concentração de $\mathrm{N}$ na uréia (45\%), sendo o nitrogênio de suma importância no metabolismo vegetal, participando diretamente da biossíntese de proteínas e clorofilas (ANDRADE et al., 2003).

Kappes et al. (2014) enfatizam que o aumento da produtividade foi favorecido pela massa de grãos, demonstrando a importância desse parâmetro para maximizar a produção. Concomitantemente, Gazola et al. (2014), também observaram uma correlação positiva entre massa de mil grãos e produtividade de milho, corroborando com os resultados apresentados neste.

\section{Conclusões}

O tratamento T3 apresentou maior diâmetro de espigas, maior teor de clorofila, maior diâmetro de espiga, maior massa de grãos por espiga e maior produtividade, quando comparado aos demais tratamentos. Os tratamentos observados não influenciaram no número de fileiras de grãos por espiga.

O fertilizante foliar Fortune ${ }^{\circledR}$ aplicado via foliar, pode contribuir para incremento na produtividade da cultura do milho, mas não consegue suprir a demanda de $\mathrm{N}$ pela cultura, quando aplicado como única forma de fornecimento de $\mathrm{N}$ inorgânico às plantas.

\section{Referências Bibliográficas}

ALVA, A. K.; PARAMASIVAM, S.; FARES, A.; DELGADO, J. A.; MATTOS JUNIOR, D.; SAJWAN, K. Nitrogen and irrigation management practices to improve nitrogen uptake efficiency and minimize leaching losses. Journal of Crop Improvement, Binghamton, v. 15, n. 2, p. 369-420, 2005.

AMADO, T. J. C.; MIELNICZUK, J.; AITA, C. Recomendação de adubação nitrogenada para o milho no RS e SC adaptada ao uso de culturas de cobertura do solo, sob sistema plantio direto. Revista Brasileira de Ciência do Solo, Viçosa-MG, v. 26, n. 1, p. 241-248, 2002.

ANDRADE, A. C.; FONSECA, D. M.; QUEIROZ, D. S.; SALGADO, L. T.; CECON, P. R. Adubação nitrogenada e potássica em capim-elefante (Pennisetum purpureum Schum. cv. Napier). Ciência e Agrotecnologia, Lavras-MG, v. 27, n. 1, p.1643-1651, 2003.

BOARETTO, A. E.; SANTOS NETO, P.; MUROAKA, T.; OLIVEIRA, M. W.; TRIVELIN, P. C. O. Fertilização foliar de nitrogênio para laranjeira em estágio de formação. Scientiae Agricola, v. 56, n. 3, 1999

CARDOSO, M. J.; SILVA, A. R.; GUIMARÃES, L. J. M.; PARENTONI, S. N.; SETUBAL, J. W. Produtividade e espiga verde de milho sob diferentes níveis de nitrogênio. Horticultura Brasileira, Brasília-DF, v. 28, n. 2, p. S3786S3789, 2010.

CHAPMAN, S. C.; BARRETO, H. J. Using a chlorophyll meter to estimate specific leaf nitrogen of tropical maize during vegetative growth. Agronomy Journal, Madison, v. 89, n.1, p. 557-562, 1997.

CONAB. COMPANHIA NACIONAL DE ABASTECIMENTO. Acompanhamento de safra brasileiro - grãos: Nono levantamento, junho 2013 - safra 2012/2013: Brasília-DF: 2013. Disponível em: http://www.conab.gov.br/OlalaCMS/uploads/arquivos/13_03_ 07_10_39_19_levantament o_safras_graos_6.pdf>. Acesso em 24 de agosto de 2016.

GAZOLA, D.; ZUCARELI, C.; SILVA, R. R.; FONSECA, I. C. B. Aplicação foliar de aminoácidos e adubação nitrogenada de cobertura na cultura do milho safrinha. Revista Brasileira de Engenharia Agrícola e Ambiental, Campina Grande-PB, v. 18 , n. 7 , p. $700-707,2014$

GODOY, J. C. S. D.; WATANABE, S. H.; FIORI, C. C. L.; GUARIDO, R. C. Produtividade de milho em resposta a doses de nitrogênio com e se inoculação das sementes com Azospirillum brasilense. Campo Digital, Campo Mourão-PR, v. 6 , n. 1, p. 26-30, 2011.

JAKELAITIS, A.; SILVA, A. A.; FERREIRA, L. R. Efeito do nitrogênio sobre o milho cultivado em consórcio com Brachiaria brizantha. Acta Scientiarum Agronomy, Maringá- PR, v.2 7, n. 1, p. 39-46, 2005.

KAPPES, C.; ARF, O.; DAL BEM, E. A.; PORTUGAL, J. R.; GONZAGA, A. R. Manejo do nitrogênio em cobertura na cultura do milho em sistema plantio direto. Revista Brasileira de Milho e Sorgo, Sete Lagoas-MG, v. 13, n. 2, p. 201-217, 2014.

LARA CABEZAS, W. A. R.; ALVES, B. J. R.; URQUIAGA, S.; SANTANA, D. G. Influência da cultura antecessora e da adubação nitrogenada na produtividade de milho em sistema plantio direto e solo preparado. Ciência Rural, Santa MariaRS, v. 34, n. 1, p. 1005-1013, 2004.

MAgAlhães, P. C.; DURÃES, F. O. M. Fisiologia da Produção do Milho. Sete Lagoas-MG: Embrapa milho e sorgo, 2006, p. 10 (Circular Técnica, 76).

OHLAND, R. A. A.; SOUZA, L. C. F.; HERNANI, L. C.; MARCHETTI, M. E.; GONÇALVES, M. C. Culturas de cobertura do solo e adubação nitrogenada no milho em plantio direto. Ciência e Agrotecnologia, Lavras-MG, v. 29, n. 3, p. 538-544, 2005.

SILVA, P. S. L.; OLIVEIRA, F. H. T.; SILVA, P. I. B. Efeitos da aplicação de nitrogênio e densidades de plantio sobre os rendimentos de espigas verdes e de grãos de milho. Horticultura Brasileira, Brasília-DF, v. 21, n. 1, p. 452-455, 2003. 
SILVEIRA, P. M.; BRAZ, A. J. B. P.; DIDONET, A. D. Uso de clorofilômetro como indicador da necessidade de adubação nitrogenada em cobertura no feijoeiro. Pesquisa Agropecuária Brasileira, Brasília-DF, v. 38, n. 9, p. $1083-$ 1087, 2003.

SOUZA, J. A., BUZETTI, S., TEIXEIRA FILHO, M. C. M. ANDREOTTI, M., SÁ, M. A. D., ARF, O. Adubação nitrogenada na cultura do milho safrinha irrigado em plantio direto. Bragantia, Campinas-SP, v. 70, n. 1, p. 447-454, 2011.
VALDERRAMA, M., BUZETTI, S., BENETT, C. G. S., ANDREOTTI, M. E MINHOTO, M. C. T. Fontes e doses de NPK em milho irrigado sob plantio direto. Pesquisa Agropecuária Tropical, Londrina-PR, v. 41, n. 2, p. 254-263, 2011. 